\title{
Multiple drug resistant Vibrio cholerae, Salmonella and Shigella from Nepalgunj Cholera outbreak and different hospitals of Nepal
}

\author{
Binod Kumar Shah ${ }^{1}$, Sapana Sharma ${ }^{1}$, Gita Shakya ${ }^{2}$ and Bishnu Prasad Upadhyay ${ }^{2}$ \\ ${ }^{1}$ National College, Khusibu, Kathmandu, Nepal \\ ${ }^{2}$ National Public Health Laboratory, Teku, Kathmandu, Nepal \\ *E-mail: binodshah120@yahoo.com; binodshah120@gmail.com
}

\begin{abstract}
Diarrhoea is a major health problem throughout the world, and responsible for high morbidity and mortality in Nepal. The crosssectional prospective study was carried out to screen ESBL producer from MDR Vibrio Cholerae, Salmonella and Shigella from 268 diarrhoeal stools from Nepalgunj Cholera outbreak and different hospitals of Nepal during April 2010 to January 2011. The specimens were processed by standard microbiological methods and confirmed with serology. Altogether $14.18 \%$ of bacteria were isolated with $8.21 \%$ $V$. cholerae O1 El Tor Ogawa, 2.24\% Shigella flexneri B and $3.73 \%$ Salmonella spp. Highest bacterial culture $(47.36 \%)$ were isolated in Kathmandu while highest $V$. cholerae $(77.27 \%)$ were isolated in Nepalgunj. The highest number of Salmonella spp. and Shigella spp. were isolated from Kanti Children's Hospital. Highest bacteria isolation $(47.36 \%)$ and highest $V$. cholerae isolation $(81.81 \%)$ were observed in the August. The bacteria isolation was significantly associated with places and months $(\mathrm{p}<0.05)$. However, there was no statistical difference in the bacteria isolation with sex $(\mathrm{P}>0.05) .100 \% \mathrm{~V}$. cholerae, $100 \%$ Shigella spp. and $80 \%$ Salmonella spp. were MDR while only one Salmonella Cholerasuis was found ESBL producer.
\end{abstract}

Key words: ESBL, MDR, Salmonella, Shigella, Vibrio cholerae

\section{Introduction}

Severe occurrence of acute diarrhoea constitutes one of the commonest challenges faced by the medical personnel and emergency treatment with special concern in the developing world and mild nuisance in the developed world. Nepal, being a developing country, faces the similar health problem as other developing countries. Diarrhea and gastroenteritis (including cholera and dysentery) comes in first position among top ten causes of OPD morbidity and second position among top ten diseases responsible for hospitalization in Nepal (DoHS, 2011). In Nepal, approximately 2 million of diarrhoeal disease incidence and 100 to 300 people deaths are reported (WHO, 2007; DoHS, 2011). Cholera is one of the most important causes of acute diarrhoea in Nepal (WHO, 2007).

Diarrhoea is a symptom of infection caused by vast etiology of bacteria, virus and parasites (Ono et al., 2001). Acute infectious diarrhoea is acquired predominantly through the faecooral route and by ingestion of water and food contaminated with pathogenic organisms (Sack et. al., 2004). The main etiology of the diarrhea is related to a wide range of bacteria 
(such as Campylobacter jejuni, Escherichia coli, Salmonella spp., Shigella spp., Vibrio cholerae, Yersinia enterocolitica, Aeromonas spp., Plesiomonas shigelloides, Edwardsella tarda), enteroparasites (Giardia spp., Cyclospora, Cryptosporidium spp., Entamoeba histolytica), and viruses (Adenovirus, Norwalk virus, Rotavirus, Astrovirus, Calicivirus and Noroviruses). Intestinal worms infect about $10 \%$ of the population of the developing world (WHO, 2004).

Low socioeconomic status, poverty, illiteracy, poor standard of environmental hygiene, inaccessibility of safe drinking water, incorrect feeding practices, inadequate sanitation, immunodeficiency etc. are the prime factors that cause increase incidence of diarrhoeal diseases in Nepal. Due to these reasons, Diarrhoea and Cholera have been included among one of the six outbreak potential diseases: Malaria, Kalaazar, Dengue, Acute gastroenteritis (AGE), Cholera and Severe Acute Respiratory Infection (SARI) under the Early Warning Reporting System (EWARS) (EDCD, 2009).

The incidence of diarrhoeal diseases rises sharply each year during the warm summer months; the small increase in the incidence of the food borne gastroenteritis occur in AprilMay, followed by a sharp rise in the incidence of water borne gastroenteritis and cholera with the beginning of monsoon rain in June. The epidemic tends to peak in July-August and subside by October (Kaper et al., 1995; Pokhrel et al., 1997).

\section{Methodology}

All the laboratory works were conducted at the bacteriology section of National Public Health Laboratory, Teku from April, 2010 to January, 2011. During this period a total of 268 diarrhoeal stool samples were collected and processed by standard microbiological methods and confirmed with serology.

Faecal specimens were collected in a clean, leak-proof container with the help of a small sterile metal/wooden/plastic spoon in the acute stages of the diarrhoeal disease. In case of stool unavailable, stool swabs were collected. The specimen was transported to the laboratory within $2 \mathrm{~h}$ at $4^{\circ} \mathrm{C}$. If a delay longer than $2 \mathrm{~h}$ was anticipated for bacterial culture, the specimen was placed in Cary-Blair transport medium (in the form of swab) and transported to the lab at $4^{\circ} \mathrm{C}$. Similarly, the specimen was transported in alkaline peptone water (APW) at $4^{\circ} \mathrm{C}$ in case of $V$. cholerae suspected. Fresh stool specimens were first examined macroscopically. The stool samples from suspected cholera patients were subjected to hanging drop preparation (Collee et al., 2006; Forbes et al., 2007).

\section{A. Culture of the Specimen}

\section{Isolation and identification of Bacteria}

Heavy inoculums of stool was inoculated on culture media MA, SS and TCBS and $2 \mathrm{ml}$ stool in $10 \mathrm{ml}$ enrichment media, Alkaline Peptone Water (APW) and S-F broth and incubated aerobically at $37^{\circ} \mathrm{C}$ for $24 \mathrm{~h}$. On the following day, in case of non-positive growth for Salmonella, Shigella and Vibrio cholerae, a loopful broth from APW and S-F was inoculated on second plates of MA, SS and TCBS and incubated aerobically at $37^{\circ} \mathrm{C}$ for $24 \mathrm{~h}$.

\section{B. Examination of culture plates}

On the following day, the inoculated plates were observed for the presence of non-lactose fermenting transparent colorless colonies on MA, non-lactose fermenting translucent 
colonies on SS and sucrose fermenting yellow, shining, button shaped colonies 2-3 $\mathrm{mm}$ in diameter, on TCBS. Yellow colonies from TCBS was sub-cultured on MA and observed for NLF colonies on the following day. The isolated colonies from the MA and SS were subcultured on NA. Gram staining was performed for gram-negative rod, curved rod bacteria and biochemical tests were performed.

\section{Serotyping and Biotyping of the isolates}

Biochemically suspected colony of Vibrio cholerae, Salmonella and Shigella were subjected to serological confirmation. Suspected colonies from TCBS, SS and MA were subcultured on NA and slide agglutination test was performed with specific antisera. Vibrio cholerae $\mathrm{O} 1$ was further classified as Classical and El Tor biovars on the basis of Haemolysis of Sheep RBC, VP reaction and Polymyxin B (50 IU) Sensitivity test.

The sensitivity of the isolates towards various antibiotics was determined by modified Kirby-Bauer M02-A10 using Mueller Hinton Agar (MHA) and MDR isolates were screened for possible ESBL production (CLSI, 2009; Mast Group, 2010; CLSI, 2011). Data were analyzed by SPSS software using chi square test.

\section{Results and Discussion}

Out of 268 patients, $113(42.16 \%)$ patients were visiting Microbiology Department of NPHL, 62 (23.13\%) from Sukraraj Tropical and Infectious Disease Hospital, 59 (22.01\%) from Kanti Children's Hospital and 34 (12.69\%) from different Diarrhoea and Cholera Outbreak Sites: Nepalgunj, Banke District ( $\mathrm{n}=26,9.70 \%)$; Dhangadhi ( $\mathrm{n}=1,0.37 \%)$; Dang $(\mathrm{n}=2,0.75 \%)$; Damauli ( $\mathrm{n}=1,0.37 \%)$; and Achham ( $\mathrm{n}=4,1.5 \%)$ (Fig. 1).

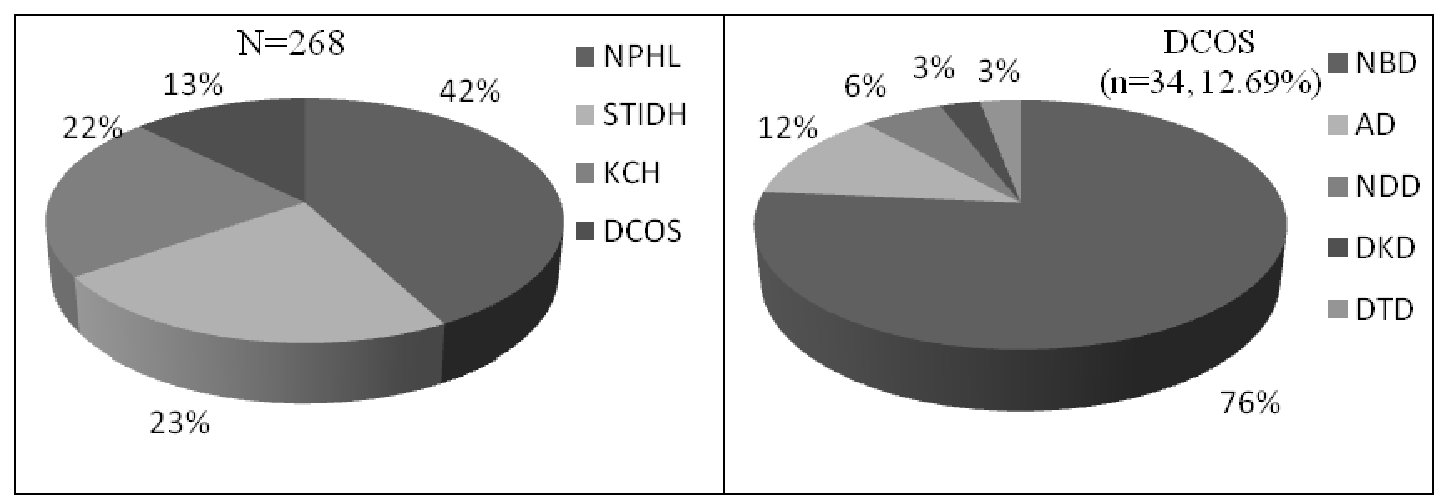

Figure 1. Distribution of samples.

NPHL = National Public Health Laboratory, Teku, Kathmandu; DCOS= Diarrhoea and Cholera Outbreak Sites; STIDH= Sukraraj Tropical and Infectious Disease Hospital, Teku, Kathmandu; $\mathrm{KCH}=$ Kanti Children's Hospital, Maharajgunj, Kathmandu; NBD = Nepalgunj, Banke District; $\mathrm{DKD}=$ Dhangadhi, Kailali District; NDD = Narayanpur, Deukhuri, Dang District; DTD $=$ Damauli, Tanahu District; $\mathrm{AD}=$ Achham District.

A total of 230 patients $(85.82 \%)$ were growth negative while 38 specimen (14.18\%) showed positive growth culture for causative bacteria including $22 \mathrm{~V}$. cholerae (8.21\%), 6 Shigella spp. (2.24\%) and 10 Salmonella spp. (3.73\%). The bacterial incidence found in this study is low in comparison to other findings such as $30 \%$ by Shrestha (2008) and $27.14 \%$ by Karki et al. (2010). The variation between the prevalence rates of enteropathogens may be due to 
different geographic set up, socioeconomic status, environmental hygiene, water and sanitary measures, study time difference and exclusion of certain enteropathogens of diarrhoea in the study, etc. Majority of samples in the present study were obtained from NPHL which was visited by variety of patients of different ages with various complains and limited number of samples were obtained from other hospitals like $\mathrm{KCH}$ and STIDH during limited short period. Antibiotics are often sold in Nepal over counter. So administration of antibiotics prior to collection of stool samples may be one of the causes of growth negativity in the study. This may be reason for only $14.18 \%$ growth positivity.

Both male and female shared $50 \%$ of samples and $14.18 \%$ culture positivity. There was no significant difference in the bacterial culture positivity with sex $(\mathrm{P}>0.05)$. During the study period, major isolates were $V$. cholerae $\mathrm{O} 1(57.89 \%)$.

Sampling site wise culture (Tab. 1) positivity was observed highest $(n=20,52.63 \%)$ at diarrhoea and cholera outbreak sites and least $(n=3,7.89 \%)$ at both NPHL and STIDH whereas place wise culture positivity was observed highest $(n=18,47.36 \%)$ in Kathmandu Valley followed by Nepalgunj $(n=17,44.73 \%)$ and least $(n=1,2.63 \%)$ in Dhangadhi. NPHL was visited by variety of patients of different ages with various complains and limited number of samples were obtained from STIDH during limited short period which made least isolation of bacteria from NPHL and STIDH samples.

Table 1. Sampling site wise distribution of bacterial isolates.

\begin{tabular}{lccccc}
\hline Bacterial isolates & NPHL & DCOS STIDH & KCH & Total \\
\hline V. cholerae O1 Ogawa El Tor & 2 & 20 & 0 & 0 & 22 \\
Shigella flexneri B & 0 & 0 & 1 & 5 & 6 \\
Salmonella spp. & 1 & 0 & 2 & 7 & 10 \\
Salmonella Paratyphi A & 0 & 0 & 0 & 1 & 1 \\
Salmonella Typhimurium & 0 & 0 & 1 & 0 & 1 \\
Salmonella Cholerasuis & 0 & 0 & 1 & 3 & 4 \\
Other Salmonella spp. & 1 & 0 & 0 & 3 & 4 \\
\hline Total & 3 & 20 & 3 & 12 & 38 \\
\hline
\end{tabular}

The bacterial culture positivity was significantly associated with places $(p<0.05)$. Highest bacterial incidence (100\%) were observed in Dang (2 isolates in 2 samples) and Dhangadhi ( 1 isolate in 1 sample), followed by Nepalgunj (17 isolates in 26 samples, 65.38\%). Highest number of $V$. cholerae (17/22 isolates, 77.27\%) were isolated from Nepalgunj. The higher incidence rate and isolation rate of $V$. cholerae from Nepalgunj (Banke), Dang and Dhangadhi (Kailali) may be due to unsafe provision of drinking water; improper management of water pipelines, sewage and excreta and less hygienic condition to that place. No any V. cholerae was isolated from samples of Kanti Children's Hospital ( $\mathrm{KCH})$ and Sukraraj Tropical Hospital (STIDH). The stool samples from the $\mathrm{KCH}$ were cultured during December and January only, but not during the rainy season. This may be the reason of culture negativity for Vibrio from the patients of $\mathrm{KCH}$. Lesser number of stool samples (only $n=62$ ) (as not all the samples were submitted to the STIDH) were cultured during rainy and post rainy season. This may be the cause of culture negativity of Vibrio from the patients of STIDH. 
Five out of six S. flexneri B were isolated from children below 12 years of $\mathrm{KCH}$ in December and January. Shigellosis is primarily a paediatric disease, around $80 \%$ of infection occurred in the age under 10 years, the majority of cases occurring in children less than 5 years old (Blaser et al., 1983). Maximum of paediatric stool samples from $\mathrm{KCH}$ were cultured during winter season. This may be the cause of isolation of majority of Shigella spp. from $\mathrm{KCH}$ in winter season in our study.

Table 2. Place and district wise distribution of bacterial isolates.

\begin{tabular}{|c|c|c|c|c|c|c|c|c|}
\hline \multirow{2}{*}{ Bacterial isolates } & \multicolumn{6}{|c|}{ Places and districts } & \multirow{2}{*}{ Total } & \multirow{2}{*}{$\%$} \\
\hline & KV & NBD & DKD & NDD & $\mathbf{A D}$ & DTD & & \\
\hline V. cholerae O1 Ogawa El Tor & 2 & 17 & 1 & 2 & 0 & 0 & 22 & 57.89 \\
\hline Shigella flexneri B & 6 & 0 & 0 & 0 & 0 & 0 & 6 & 15.78 \\
\hline Salmonella spp. & 10 & 0 & 0 & 0 & 0 & 0 & 10 & 26.31 \\
\hline Salmonella Paratyphi A & 2 & 0 & 0 & 0 & 0 & 0 & 2 & 2.63 \\
\hline Salmonella Typhimurium & 1 & 0 & 0 & 0 & 0 & 0 & 1 & 2.63 \\
\hline Salmonella Cholerasuis & 4 & 0 & 0 & 0 & 0 & 0 & 4 & 10.52 \\
\hline Other Salmonella spp. & 3 & 0 & 0 & 0 & 0 & 0 & 3 & 10.52 \\
\hline Total & 18 & 17 & 1 & 2 & 0 & 0 & 38 & 100.0 \\
\hline$\%$ & 47.36 & 44.73 & 2.63 & 5.26 & 0 & 0 & 100.0 & \\
\hline
\end{tabular}

$\mathrm{KV}=$ Kathmandu valley; NBD= Nepalgunj, Banke district; $\mathrm{DKD}=$ Dhangadhi, Kailali district; $\mathrm{NDD}=$ Narayanpur, Deukhuri, Dang district; $\mathrm{DTD}=$ Damauli, Tanahu district; $\mathrm{AD}=$ Achham district.

The highest number of Salmonella spp. (7/10 isolates) were isolated from Kanti Children's Hospital during December and January. This may be due the fact that more stools samples from Kanti children's Hospital were processed during the months of December and January and children when they are more prone to environmental Salmonella infections. Only one Salmonella spp. was isolated from the patients visiting NPHL during July and two Salmonella spp. from patients of Sukraraj Tropical and Infectious Disease Hospital, Teku during June. Generally, NPHL is visited by variety of patients of different ages with different complains. This may be the reason that lesser isolation was from NPHL.

Table 3. Seasonal distribution of Bacterial isolates (April, 2010-January, 2011).

\begin{tabular}{lcccccccc}
\hline \multirow{2}{*}{ Months } & \multicolumn{3}{c}{ Total bacterial isolates } & \multicolumn{3}{c}{ V. cholerae O1 } & \multicolumn{3}{c}{ Shigella flexneri } & \multicolumn{3}{c}{ Salmonella spp. } \\
\cline { 2 - 9 } & No. & $\%$ & No. & $\%$ & No. & \% & No. & $\%$ \\
\hline April & - & - & - & - & - & - & - & - \\
May & - & - & - & - & - & - & - & - \\
June & 2 & 5.26 & - & - & - & - & 2 & 20.0 \\
July & 3 & 7.89 & 2 & 9.09 & - & - & 1 & 10.0 \\
August & 18 & 47.36 & 18 & 81.81 & - & - & - & - \\
September & 1 & 2.63 & 1 & 4.54 & - & - & - & - \\
October & - & - & - & - & - & - & - & - \\
November & 2 & 5.26 & 1 & 4.54 & 1 & 16.66 & - & - \\
December & 11 & 28.94 & - & - & 5 & 83.33 & 6 & 60.0 \\
January & 1 & 2.63 & - & - & - & - & 1 & 10.0 \\
\hline Total & 38 & 100.0 & 22 & 100.0 & 6 & 100.0 & 10 & 100.0 \\
\hline
\end{tabular}


During the study period of 10 months, the maximum percentage of bacteria was isolated in August (47.36\%), followed by December (28.94\%), July (7.89\%) and the least isolation in both September and January (2.63\%). In Nepal, diarrhoea and cholera outbreaks occur each year commonly from June to November i.e. in rainy and post rainy season, the peak period being June and August suggesting favourable condition for its proliferation. The increase in rainfall, temperature and relative humidity are contributing environmental factors for rapid contamination and transmission of pathogens in huge dosage (Pokhrel et al. 1997, Shrestha 1995). In the month of September and July, more samples from adult and less from children visiting NPHL and STIDH were cultured; while in the month of December and January, maximum samples cultured were from the children of $\leq 12$ years old from Kanti Children's Hospital who are more prone to Shigellosis and Salmonellosis due to lack of immunity towards these diseases in the younger age. This may be the cause of higher number of isolation of bacteria in the month of December in comparison to September and July. The bacterial culture positivity was significantly associated with months $(\mathrm{p}<0.05)$.

Table 4. AST pattern of V. cholerae O1 (n=22).

\begin{tabular}{|c|c|c|c|c|c|c|}
\hline \multirow{2}{*}{ Antibiotics } & \multicolumn{2}{|c|}{ Sensitive } & \multicolumn{2}{|c|}{ Intermediate } & \multicolumn{2}{|c|}{ Resistant } \\
\hline & No. & $\%$ & No. & $\%$ & No. & $\%$ \\
\hline $\mathrm{AK}$ & 5 & 22.72 & 6 & 27.27 & 11 & 50.0 \\
\hline $\mathrm{A}$ & 12 & 54.54 & 2 & 9.09 & 8 & 36.36 \\
\hline AZM & 22 & 100.0 & - & - & - & - \\
\hline CFM & 21 & 95.45 & - & - & 1 & 4.45 \\
\hline CPM & 22 & 100.0 & - & - & - & - \\
\hline CTX & 20 & 90.90 & 2 & 9.09 & - & - \\
\hline CAZ & 16 & 72.72 & 6 & 27.27 & - & - \\
\hline CPD & 21 & 95.45 & 1 & 4.45 & - & - \\
\hline $\mathrm{CRO}$ & 21 & 95.45 & 1 & 4.45 & - & - \\
\hline CIP & 13 & 59.09 & 7 & 31.81 & 2 & 9.09 \\
\hline $\mathrm{C}$ & 17 & 77.27 & 4 & 18.18 & 1 & 4.54 \\
\hline $\mathrm{TS}$ & - & - & - & - & 22 & 100.0 \\
\hline $\mathrm{E}$ & 18 & 81.81 & 3 & 13.63 & 1 & 4.54 \\
\hline FR & - & - & - & - & 22 & 100.0 \\
\hline $\mathrm{G}$ & 22 & 100.0 & - & - & - & - \\
\hline OFX & 18 & 81.81 & 2 & 9.09 & 2 & 9.09 \\
\hline $\mathrm{T}$ & 4 & 18.18 & - & - & 18 & 81.81 \\
\hline
\end{tabular}

$\mathrm{AK}=$ Amikacin, $\mathrm{A}=$ Amoxycillin, $\mathrm{AZM}=$ Azithromycin, $\mathrm{CFM}=$ Cefexime, $\mathrm{CPM}=$ Cefepime, $\mathrm{CTX}=$ Cefotaxime, $\mathrm{CAZ}=$ Ceftazidime, $\mathrm{CPD}=$ Cefpodoxime, $\mathrm{CRO}=$ Ceftriazone, $\mathrm{CIP}=$ Ciprofloxacine, $\mathrm{C}=$ Chloramphenicol, $\mathrm{TS}=$ Cotrimoxazole, $\mathrm{E}=$ Erythromycin, $\mathrm{FR}=$ Furazolidone, $\mathrm{G}=$ Gentamycin, $\mathrm{OFX}=$ Ofloxacin, $\mathrm{T}=$ Tetracycline

Altogether 36 (94.73\%) enteric bacteria were found to be multidrug resistant (MDR) i.e. resistant to two or more than two classes of antibiotics used and only one isolate $(2.63 \%)$ among all was sensitive to all drugs which was $10 \%$ of Salmonella isolates. Among all isolates, $100 \%$ Vibrio were MDR followed by $100 \%$ Shigella and $80 \%$ Salmonella spp. A single isolate (2.63\%) was resistant to a single drug; 7 isolates (18.42\%) resistant to 2 drugs, 
8 isolates $(21.05 \%)$ resistant to 3 drugs, 10 isolates (26.31\%) resistant to 4 drugs, 3 isolates $(7.89 \%)$ resistant to 5 drugs, 5 isolates $(13.15 \%)$ resistant to 6 drugs, 2 isolates $(5.26 \%)$ resistant to 7 drugs and 1 isolate $(2.63 \%)$ resistant to 11 drugs. Among all isolates, a single isolate $(2.63 \%)$ was found to be ESBL positive which was Salmonella cholerasuis resistant to 11 antibiotics. There is significant association between bacterial species and occurrence of ESBL status $(\mathrm{P}<0.05)$.

Table 5. AST pattern of Shigella flexneri B $(\mathrm{n}=6)$.

\begin{tabular}{ccccccccc}
\hline \multirow{2}{*}{ Antibiotics } & \multicolumn{2}{c}{ Sensitive } & & \multicolumn{2}{c}{ Intermediate } & & \multicolumn{2}{c}{ Resistant } \\
\cline { 2 - 3 } \cline { 8 - 9 } & No. & $\%$ & & No. & \% & & No. & \% \\
\hline AK & 3 & 50.0 & & 1 & 16.67 & & 2 & 33.33 \\
A & 2 & 33.33 & & - & - & & 4 & 66.67 \\
AZM & 5 & 83.33 & & - & - & & 1 & 16.67 \\
CFM & 6 & 100.0 & & - & - & & - \\
CPM & 6 & 100.0 & & - & - & & - & - \\
CTX & 6 & 100.0 & & - & - & & - \\
CAZ & 6 & 100.0 & & - & - & & - & - \\
CPD & 6 & 100.0 & & - & - & & - & - \\
CRO & 6 & 100.0 & - & - & & - \\
CIP & 2 & 33.33 & & - & - & & 4 & 66.67 \\
C & 3 & 50.0 & & - & - & & 3 & 50.0 \\
TS & 2 & 33.33 & & - & - & & 4 & 66.67 \\
G & 6 & 100.0 & & - & - & & - & - \\
OFX & 2 & 33.33 & & - & - & & 4 & 66.67 \\
T & 1 & 16.67 & & - & - & & 5 & 83.33 \\
\hline
\end{tabular}

Table 6. AST pattern of Salmonella species $(\mathrm{n}=10)$.

\begin{tabular}{|c|c|c|c|c|c|c|}
\hline \multirow{2}{*}{ Antibiotics } & \multicolumn{2}{|c|}{ Sensitive } & \multicolumn{2}{|c|}{ Intermediate } & \multicolumn{2}{|c|}{ Resistant } \\
\hline & No. & $\%$ & No. & $\%$ & No. & $\%$ \\
\hline AK & 4 & 40.0 & 1 & 10.0 & 5 & $\overline{50.0}$ \\
\hline $\mathrm{A}$ & 4 & 40.0 & - & - & 6 & 60.0 \\
\hline AZM & 1 & 10.0 & 3 & 30.0 & 6 & 60.0 \\
\hline CFM & 8 & 80.0 & - & - & 2 & 20.0 \\
\hline CPM & 9 & 90.0 & - & - & 1 & 10.0 \\
\hline CTX & 9 & 90.0 & - & - & 1 & 10.0 \\
\hline CAZ & 7 & 70.0 & 2 & 20.0 & 1 & 10.0 \\
\hline CPD & 9 & 90.0 & - & - & 1 & 10.0 \\
\hline CRO & 8 & 80.0 & 1 & 10.0 & 1 & 10.0 \\
\hline CIP & 6 & 60.0 & 2 & 20.0 & 2 & 20.0 \\
\hline $\mathrm{C}$ & 9 & 90.0 & - & - & 1 & 10.0 \\
\hline $\mathrm{TS}$ & 7 & 70.0 & - & - & 3 & 30.0 \\
\hline $\mathrm{G}$ & 9 & 90.0 & - & - & 1 & 10.0 \\
\hline OFX & 7 & 70.0 & 2 & 20.0 & 1 & 10.0 \\
\hline $\mathrm{T}$ & 1 & 10.0 & 5 & 50.0 & 4 & 40.0 \\
\hline
\end{tabular}


Table 7. Distribution of Multiple Drug Resistant (MDR) enteric bacterial isolates.

\begin{tabular}{|c|c|c|c|c|c|c|}
\hline \multicolumn{3}{|c|}{ Type and No. of bacteria } & $\begin{array}{c}\text { V. cholerae } \\
\text { (22) }\end{array}$ & $\begin{array}{c}\text { Shigella } \\
\text { flexneri(6) }\end{array}$ & $\begin{array}{c}\text { Salmonella } \\
\text { spp. (10) }\end{array}$ & Total (38) \\
\hline Sensitive & all drugs & $\mathrm{d}(\%)$ & - & - & $1(10 \%)$ & $1(2.63 \%)$ \\
\hline \multirow{16}{*}{ 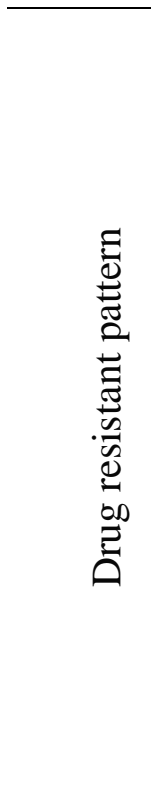 } & \multirow{2}{*}{1 drug } & No. & - & - & 1 & 1 \\
\hline & & $\%$ & - & - & $10.0 \%$ & $2.63 \%$ \\
\hline & \multirow{2}{*}{ 2drugs } & No. & 1 & 2 & 4 & 7 \\
\hline & & $\%$ & $4.54 \%$ & $33.33 \%$ & $40.0 \%$ & $18.42 \%$ \\
\hline & \multirow{2}{*}{ 3drugs } & No. & 7 & - & 1 & 8 \\
\hline & & $\%$ & $31.81 \%$ & . & $10.0 \%$ & $21.05 \%$ \\
\hline & \multirow{2}{*}{ 4drugs } & No. & 9 & 1 & - & 10 \\
\hline & & $\%$ & $40.9 \%$ & $16.67 \%$ & - & $26.31 \%$ \\
\hline & \multirow{2}{*}{ 5drugs } & No. & 3 & - & - & 3 \\
\hline & & $\%$ & $13.63 \%$ & - & - & $7.89 \%$ \\
\hline & \multirow{2}{*}{ 6drugs } & No. & 1 & 3 & 1 & 5 \\
\hline & & $\%$ & $4.54 \%$ & $50.0 \%$ & $10.0 \%$ & $13.15 \%$ \\
\hline & \multirow{2}{*}{ 7drugs } & No. & 1 & - & 1 & 2 \\
\hline & & $\%$ & $4.54 \%$ & - & $10.0 \%$ & $5.26 \%$ \\
\hline & \multirow{2}{*}{ 11drugs } & No. & - & - & 1 & 1 \\
\hline & & $\%$ & - & - & $10.0 \%$ & $2.63 \%$ \\
\hline \multicolumn{3}{|c|}{$\begin{array}{l}\text { Total MDR (resistant to } \\
\geq 2 \text { antibiotics of different No. } \\
\text { classes) strains }\end{array}$} & 22 & 6 & 8 & 36 \\
\hline
\end{tabular}

\section{Acknowledgements}

We are thankful to National Public Health Laboratory, Teku, Kathmandu, Ms. Sirjana Devi Shrestha and Prof. Dr. Bharat Mani Pokharel for their kind help and cooperation.

\section{References}

Blaser, M.J., J.G. Wells, R.A. Fledman, R.A. Pollard \& J.R. Allen. 1983. Collaborative Diarrhoeal Disease Study Group Campylobacter enteritis in United States; A Multicenter Study. Ann. Intern. Med. 98: 360-365.

CLSI. 2009. Performance Standards for Antimicrobial Disk Susceptibility Tests; Approved Standard (10 ${ }^{\text {th }}$ Ed.). CLSI M02-A10. Vol. 29, No. 1. Clinical and Laboratory Standards Institute, Wayne, PA.

CLSI. 2011. Performance Standards for antimicrobial susceptibility testing; 21st informational supplement. CLSI M100-S21: Vol. 31, No. 1. Clinical and Laboratory Standards Institute, Wayne, PA.

Collee, J.G., A.G. Fraser, B.P. Marmion \& A. Simmons. 2006. Mackie and McCartney Practical Medical Microbiology $\left(14^{\text {th }}\right.$ Ed.). Churchil Livingstone, an imprint of Elsevier. Reed Elsevier India Pvt. Ltd. pp. 95-122.

DoHS. 2011. Annual Report 2009/10. Department of Health Services (DoHS), Ministry of Health, Government of Nepal, Teku, Kathmandu, Nepal. 64p. 
EDCD. 2009. Early Warning Reporting System (EWARS) guidelines (4 ${ }^{\text {th }}$ Ed.). Epidemiology and Disease Control Division, Department of Health Services, Ministry of Health, HMG of Nepal. pp. 1-13.

Forbes, B.A., D.F. Sahm \& A.S. Weissfeld. 2007. Baily and Scott's Diagnostic Microbiology (12 ${ }^{\text {th }}$ Ed.). Mosby Elsevier. pp. 62-77 \& 873-890.

Kaper, J.B., J.G. Jr. Morris \& M.M. Levine. 1995. Cholera. Clinical Microbiology Review. pp. 48-86.

Karki, R., D.R. Bhatta, S. Malla \& S.P. Dumre. 2010. Cholera Incidence among diarrhoeal patients visiting National Public Health Laboratory, Nepal. Japanese Journal of Infectious Disease 63: 185-187.

Mast Group Ltd. 2010. MASTDISCS ${ }^{\text {TM }}$ ID Extended Spectrum beta-lactamase (ES $\beta$ L) Detection Discs (D67C). Mast diagnostics, Mast House, U.K.

Ono, K., S.K. Rai, M. Chikahira, T. Fujimoto, H. Shibata, Y. Wada, H. Tsuji, Y. Oda, G. Rai, C.D. Shrestha, K. Masuda, H.G. Shrestha, T. Matsumura, H. Hotta, T. Kawamura \& S. Uga. 2001. Seasonal distribution of enteropathogens detected from diarrheal stool and water samples collected in Kathmandu, Nepal. Southeast Asian Journal of Tropical Medicine and Public Health 32(3): 520-526.

Pokhrel, B.M., B.R. Prasai, T. Kubo, A.P. Sharma, N.R. Tuladhar, S.P. Shrestha, C. Gurung \& H. Ohara. 1997. Bacteriology of diarrhoea in Nepal. Journal of Institute of Medicine 19: 128-13.

Sack, D.A., R.B. Sack, G.B. Nair \& A.K. Siddique. 2004. Seminar: Cholera. Lancet 363: 22333.

Shrestha, K.D. 1995. Acute diarrhoeal cases in Nepal during outbreak season. An epidemiological review. Journal of Nepal Medical Association 33: 219-231.

Shrestha, S.D. 2008. Etiology of Diarrhoea with Reference to Multiple Drug Resistant Enteric Bacterial Pathogens. Nepal Journal of Science and Technology 9: 131-138.

WHO. 2004. Water, Sanitation and Hygiene links to Health: Facts and Figures. Geneva.

WHO. 2007. Communicable disease risk assessment and interventions. In: Flooding disaster: Nepal. WHO/CDS/NTD/DCE/2007. 